\title{
Non-smoker and Non-Drinker Farmer with Oral Squamous Cell Carcinoma
}

\author{
Herlambang Devianto, ${ }^{1}$ Titis Desiandrin, ${ }^{1}$ Desiana Radithia, ${ }^{1}$ Dwi Hari Susilo ${ }^{2}$ and Alphania Rahniayu ${ }^{2}$ \\ ${ }^{1}$ Department of Oral Medicine, Faculty of Dental Medicine, Universitas Airlangga, Surabaya, Indonesia \\ ${ }^{2}$ Oncology Hospital Surabaya, Indonesia
}

\begin{abstract}
Oral Squamous Cell Carcinoma (OSCC) is a malignancy commonly found in the oral cavity with incidence rate of $90 \%$. We reported a 63-year-old male patient, non-smoker and non-drinker farmer, complaining of pain, itching, and stickiness in his tongue for the past 5 weeks. The lesion was treated with a topical anti-inflammatory medication and mouthwash, but did not heal. This case is an OSCC management and need to be alerted to the agricultural sector.
\end{abstract}

Key Words: Squamous Cell Carcinoma, farmers, carcinogenesis

\section{INTRODUCTION}

Smoking and alcohol consumption are common risk factors in developing oral squamous cell carcinoma (OSCC), but can also be developed even without that habit. The role of the environment such as sun and pesticide exposure can cause DNA damage. OSCC is a malignancy in the oral cavity with incidence rate of $90 \%$. Overall, oral cancer occupies a sequence 6 to 9 anatomically compared to cancer in other parts of the body. This disease usually attacks adults and the elderly with a clinical manifestation of ulcers, presence of necrotic tissues in the middle of the lesion and surrounded by elevated rolled borders. ${ }^{1}$ Risk factors that often causes OSCC growth are smoking and alcohol consumption, but it does not rule out the possibility of OSCC developing even without the habits. ${ }^{2,3}$

\section{CASE REPORT}

A 63-year-old man who works as a farmer came to Universitas Airlangga Dental Hospital with complaints of ulcers under his tongue that appeared approximately five weeks ago. Initially, the patient claimed his tongue was bitten by his right posterior tooth and a small wound was formed. Two weeks later, an extraction of the tooth by his dentist was performed. The ulcer did not heal but even grew bigger. The patient visited his dentist and he was given a mouthwash and topical medicine but he complained even more and the ulcer grew bigger. The patient took the initiative to have his condition checked at the Dr. Soedono Regional Hospital. There was no progress in the healing of his ulcer lesion, instead it grew bigger so the patient felt pain, itchy, and sticky in his tongue. When he gargles his mouth would feel a burning sensation.

On clinical examination, there were ulcers under his tongue, approximately $2 \times 2 \mathrm{~cm}$, solitary, yellowish, 
with irregular edges and induration, hard on palpation, had clear borders, and the area was reddish and easily bled (Figure 1). After examination and palpation of the submandibular gland, the ulcer became palpable, the nodules became solitary, approximately $1 \times 2 \mathrm{~cm}$ in size, with regular edges, clear borders, spongy consistency, easily moved and was painless. The patient claimed he never smoked nor consumed alcohol since he was in his tender years. He worked as a farmer and he never used masks when he sprayed pesticides in his work. There is no history of cancer in his family.

The patient was given chlorehexidine digluconate $0,2 \%$ spray for the ulcers in his tongue. It was recommended to be used twice daily, using up to 12 shots of the spray each time.

On the peripheral blood examination obtained hemoglobin was $14.4 \mathrm{~g} / \mathrm{dL}$ [Normal $13.5-16.6 \mathrm{~g} / \mathrm{dl}$ ], red blood cells was $5.38 \times 10^{6} / \mathrm{uL}$ [Normal $3.69-5.46 \times 10^{6 /} \mathrm{uL}$, hematocrit was $43.0 \%$ [Normal $41.3-52.1 \%$ ], leucocytes was $9.14 \times 10$ 3/uL [Normal $3.37-10^{3} / \mathrm{uL}$ ] and platelet was $390 \times 10^{3} / \mathrm{uL}$ [Normal $150-450 \times 10^{3} / \mathrm{uL}$ ], glucose fasting was $114 \mathrm{mg} / \mathrm{dL}$ [Normal < 100], blood glucose 2 hours PP (post-prandial) was $161 \mathrm{mg} / \mathrm{dL}$ [Normal 140], HbA1C was $6.1 \%$ [Normal $4.5-6.2 \%$ ], SGOT was $20.0 \mathrm{U} / \mathrm{L}$ [Normal $0-50 \mathrm{U} / \mathrm{L}$ ], SGPT was $29.0 \mathrm{U} / \mathrm{L}$ [Normal $0-50 \mathrm{U} / \mathrm{L}$ ]. Pathology examination was done with scrappings obtained from the anaplasia epithelial cell group, with rounded nucleus, pleomorphic, rough chromatin, prominent nuclei, bluishcolored cytoplasm and among them appeared the spread of PMN (polymorphonuclear) and mononuclear inflammatory cells and necrotic debris. It was concluded that the lesion was Oral Squamous Cell Carcinoma (OSCC).

The follow-up therapy was hemiglossectomy, then followed by a histopathology examination obtaining the invasive squamous cell carcinoma, moderately differentiated, perineural invasion was present, metastasis in 1 out of 36 lymph nodes, Stage III pT3N1M0, Right Neck, Right FND: Present Metastatic of Squamous Cell Carcinoma in 1 out of 36 Lymph Nodes; Less Than $3 \mathrm{~cm}$; Without Extranodal (Figures 2 and 3).

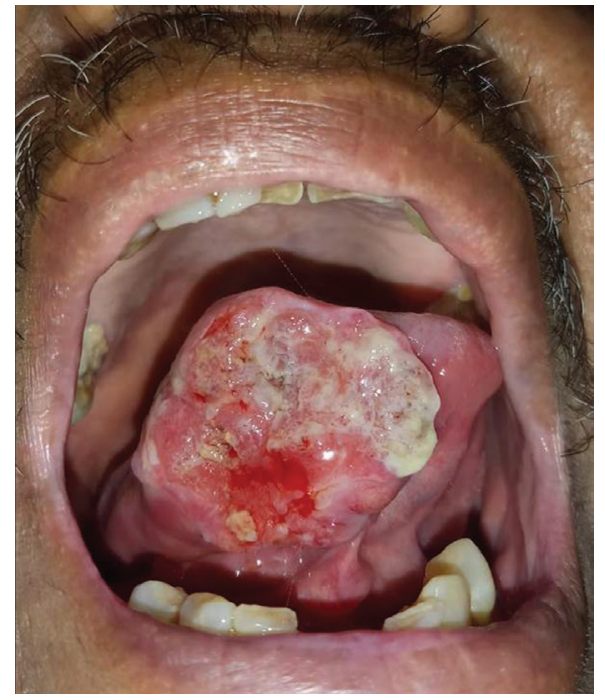

Figure 1. There were ulcers with irregular edges and induration.
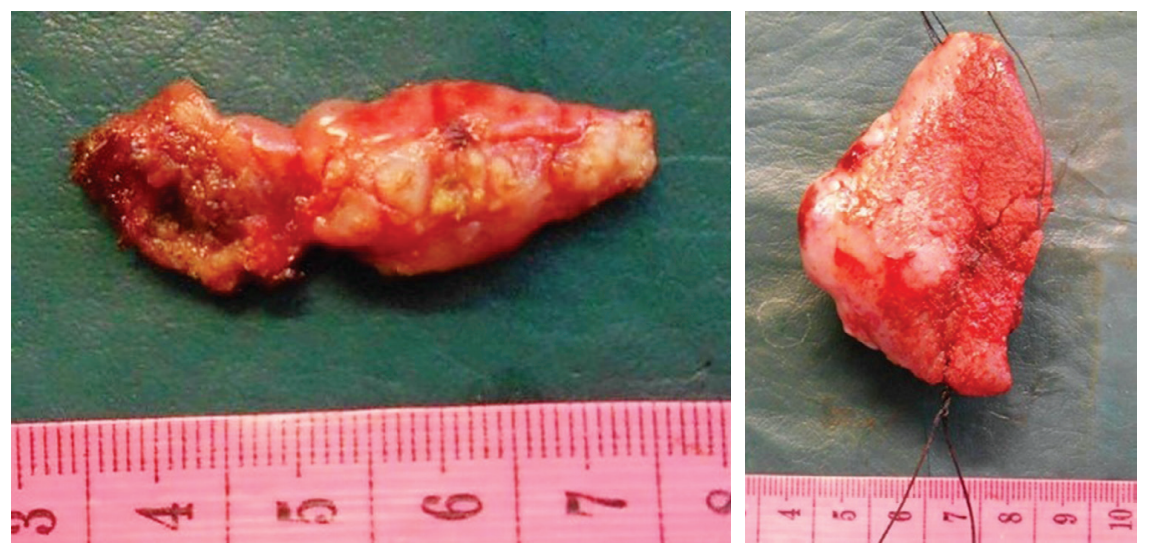

Figure 2. Right hemiglossectomy specimen.

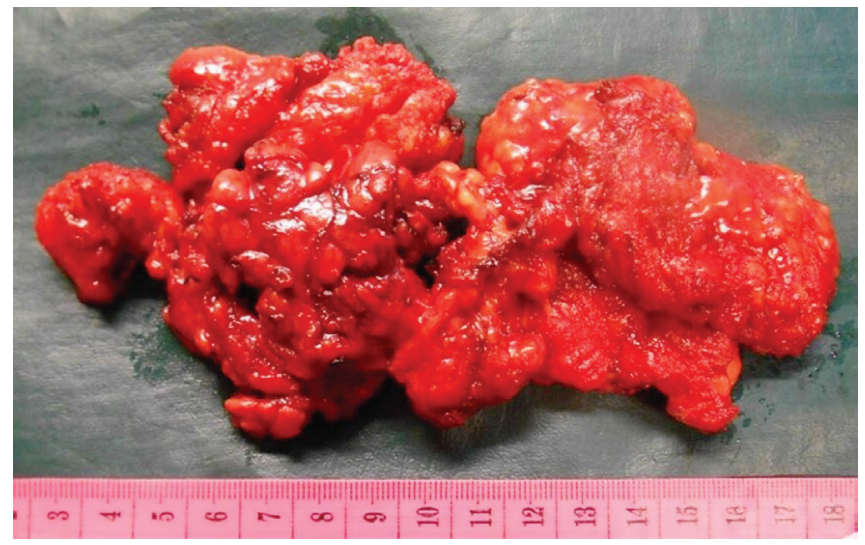

Figure 3. Right FND specimen. 


\section{DISCUSSION}

In this case study, the patient thought his tongue was bitten, creating a small wound, an ulcer was formed and was considered normal. From the case history, the patient was a farmer, was a non-smoker and non-alcohol drinker. As a farmer, he usually sprays pesticides without the use of a mask. Blood tests showed no abnormalities related to systemic conditions. The ulcer did not heal but grew even bigger. The clinical manifestations after 5 weeks was ulcer, $2 \times 2 \mathrm{~cm}$ in size, with indurated edges, with necrotic tissue in the middle with hard palpations giving a strong suspicion that the lesion was OSCC. ${ }^{4}$ As a dentist it was necessary to ascertain the ulcer lesions resembling a malignancy and to consider the patient's work to be able to predict a diagnosis of the lesion. The ulcer was treated with $0.2 \%$ chlorehexidine digluconate as an antiseptic with a longlasting antibacterial activity and with broad-spectrum bactericidal that can reduce plaque, inflammation and bleeding. ${ }^{5}$ There are several supporting examinations for the diagnosis of OSCC. The chosen method was cytology (Scrap, FNAB) because this method was easy to apply and was practical, was painless and very helpful for making a diagnosis for lesions that have a high risk of malignancy with sensitivity value of $83.1 \%{ }^{6}$

Possible therapies for OSCC to date are surgery, radiotherapy, chemotherapy, oral rehabilitation, dental extractions, palliative care, etc. A multidisciplinary approach is needed to determine the right diagnosis and treatment plan. The method of determining the stage by the Union for International Cancer Control (UICC) / American Joint Committee on Cancer (AJCC) has been developed for years, where tumors are determined by tumor size $(\mathrm{T})$, nodal status $(\mathrm{N})$ and distant metastases $(\mathrm{M})$. The function of determining this TNM is to determine the therapeutic plan, determine the prognosis, evaluate the results of therapy, exchange information between health services and for research on human cancer. In the Clinical Staging phase (cTNM) is determined based on pretreatment examinations such as biopsy, clinical examination, photographs and sometimes with examination under the influence of anesthesia. Patients who went surgery also have pathological staging (pTNM). Table 1 shows the TNM classification on the OSCC. ${ }^{7,8}$ In general, tongue OSCC which causes the incidence of nodal metastases depends on the tumor stage, if metastases are proven, then selected neck dissection has proven as effective therapy to date. ${ }^{9}$
Risk factors for OSCC cases are smoking and alcohol consumption. Infections from the Human Papiloma Virus and low consumption of fruits and vegetables are also predisposing factors. However not everyone who has this habit has OSCC risk. Epidemiologically, men are more susceptible to OSCC than women with a ratio of $1.5: 1$. In the United States, the average age of patients with OSCC is 62 years old. The exact cause is not known to date, but genetic and environmental influences are suspected as the cause of OSCC. In the agricultural environment it is possible for farmers to be vulnerable to the disease due to their exposure to sun and pesticides. ${ }^{10,11}$

Sun exposure stimulates melanocytes to produce melanin and indicates damage to the skin and DNA. ${ }^{12}$ DNA damage can cause the apoptosis process to be disrupted, one of which is the failure of activation of caspsae 3 which is the effector caspase of apoptosis. In the use of agricultural pesticides, the most commonly used ingredient is imidaclorpid (IMI), which was used since 1991 as an insecticide. There have been no studies related to the relationship between exposure to IMI and OSCC in the agricultural environment, but exposure to IMI can cause histopathological changes, activating the TNF- $\alpha$ and disturbing caspase 3 in carp. We know that the carcinogen process in humans is activated by the activation of TNF- $\alpha$ followed by the occurrence of apoptotic failure with the effector caspase disruption indicator (caspase 3) and continuous exposure to IMI can cause mutagenic and carcinogenic effects in humans and animals. ${ }^{13,14}$

\section{CONCLUSION}

OSCC is a malignancy in the oral cavity whose etiology is still unknown. Smoking and alcohol consumption are believed to be risk factors. In addition to these bad habits, environmental factors are thought to have a close relationship with OSCC, especially in an agricultural environment where farmers are often exposed to sunlight and pesticides. Continuous exposure to sun and pesticides can be the cause of OSCC even though, in the case presented, there was no history of smoking and alcohol consumption. To date, there are no epidemiological studies in the agricultural environment in Indonesia relating the prevalence of cancer in oral cavity.

\section{Acknowledgments}

We thank Prof. Diah Savitri DDS., PhD., Oral Medicine Specialist (Head of Oral Medicine Department, Faculty of Dental Medicine, Universitas Airlangga), R

Table 1. Classification of cancer stage (AJCC)

\section{Primary tumour ( $\mathrm{T})$ \\ Regional Lymph Nodes (N)}

TO : No evidence of tumour size

Tis: Carcinoma in situ

T1, T2, T3, T4 : increasing size

TX : Primary Tumour cannot be assessed
NO : No regional lymph nodes metastases

N1, N2, N3 : Increasing number lymph nodes involvement

NX : Regional lymph nodes cannot be assessed
Distant Metastase (M)

M0 : No distant metastases

M1 : distant metastases present 
Darmawan Setijanto, DDS.,PhD (Dean of Dental Medicine Faculty, Universitas Airlangga) and to the Oncology Hospital Surabaya.

\section{Statement of Authorship}

All authors participated in data collection and analysis, and approved the final version submitted.

\section{Author Disclosure}

All authors declared no conflict of interest.

\section{Funding Source}

None.

\section{REFERENCES}

1. Pires FR, Ramos AB, Oliveira JB, Tavares AS, Luz PS, Santos TC. Oral squamous cell carcinoma: clinicopathological features from 346 cases from a single Oral Pathology service during an 8-year period. J Appl Oral Sci. 2013 Sep-Oct; 21(5):460-7.

2. Chinn SB, Myers JN. Oral cavity carcinoma: Current management, controversies, and future directions. J Clin Oncol. 2015 Oct; 33(29):3269-76.

3. Carvalho KM, Sawant PR, Dhupar A, Spadigam A. A case of oral squamous cell carcinoma in a nontobacco habitué. Int J Appl Basic Med Res. 2017 Oct-Dec; 7(4):278-80.

4. Nelonda R, Setiadhi R. Management of chronic traumatic ulcer mimicking oral squamous cell carcinoma on the tongue. Dental Journal (Majalah Kedokteran Gigi). 2018 Jun; 51(2):76-80.
5. Abraham HM, Philip JM, Kruppa J, Jain AR, Krishnan CJV. Use of chlorhexidine in implant dentistry. Biomed Pharmacol J. 2015 Oct; 8SE:341-5.

6. Carreras-Torras C, Gay-Escoda C. Techniques for early diagnosis of oral squamous cell carcinoma: Systematic review. Med Oral Patol Oral Cir Bucal. 2015 May; 20(3):e305-15.

7. Pezzoli M, Bona Galvagno M, Bongioannini G. Oral squamous cell carcinoma in a patient treated with long-term pegylated liposomal doxorubicin for recurrent ovarian cancer. BMJ Case Rep. 2015 Jan; 2015:2014-6.

8. American Joint Commitee on Cancer. AJCC Cancer Staging System. 2016;17-38.

9. Pugazhendi SK, Thangaswamy V, Venkatasetty A, Thambiah L. The functional neck dissection for lymph node neck metastasis in oral carcinoma. J Pharm Bioallied Sci. 2014 Aug; 4(Suppl 2):S245-7.

10. Gupta N, Gupta R, Acharya AK, Patthi B, Goud V, Reddy S, et al. Changing Trends in oral cancer - a global scenario. Nepal J Epidemiol. 2016 Dec; 6(4):613-9.

11. Bezerra KFO, Menezes-Silva R, Oliveira DWD, Granville -Garcia AF, Alvez PM, Nonaka CFW, et al. Occupation And Oral Cavity And Pharyngeal Squamous Cell Carcinoma : A Case-Control Study. ROBRAC. 2017; 26(79):9-15.

12. Watson M, Holman DM, Maguire-Eisen M. Ultraviolet radiation exposure and its impact on skin cancer risk. Semin Oncol Nurs. 2016 Aug; 32(3):241-54.

13. Ozdemir S, Altun S, Arslan H. Imidacloprid exposure cause the histopathological changes, activation of TNF-alpha, iNOS, 8-OHdG biomarkers, and alteration of caspase 3, iNOS, CYP1A, MT1 gene expression levels in common carp (Cyprinus carpio L.). Toxicol Rep. 2017 Dec; 5:125-33.

14. Vinay K, Abbas AK, Aster JC. Robbins and Cotran Patahologic Basis of Disease, 9th ed. Philadelphia: Elsevier Saunders; 2015. p.1391. 